\title{
Host preference and habitat segregation among Red Sea anemonefish: effects of sea anemone traits and fish life stages
}

\author{
Lindsay K. Huebner ${ }^{1, *}$, Brianna Dailey ${ }^{1}$, Benjamin M. Titus ${ }^{1}$, Maroof Khalaf ${ }^{2}$, \\ Nanette E. Chadwick ${ }^{1}$ \\ ${ }^{1}$ Department of Biological Sciences, Auburn University, Auburn, Alabama 36849, USA \\ ${ }^{2}$ Department of Marine Biology, The University of Jordan-Aqaba, Aqaba 77110, Jordan
}

ABSTRACT: Competition drives habitat segregation between adults and juveniles in many types of organisms, but little is known about this process in anemonefish that compete for host sea anemones which differ in habitat quality. We performed field and laboratory experiments to determine causes of habitat segregation in 2-band anemonefish Amphiprion bicinctus on coral reefs in the northern Red Sea, where juvenile fish mainly occupy leathery sea anemones Heteractis crispa, and breeding adults almost exclusively inhabit bulb-tentacle sea anemones Entacmaea quadricolor. E. quadricolor were usually larger than H. crispa, and expanded more in response to fish presence. Adult fish visually concealed a larger proportion of their body surface area among the relatively thick tentacles of $E$. quadricolor than among the thinner tentacles of $H$. crispa, while juveniles were concealed equally well in both hosts. During field experiments, vacated E. quadricolor were colonized rapidly by fish, whereas $H$. crispa were not. In laboratory choice experiments, fish at all post-settlement life stages preferred E. quadricolor, and large individuals monopolized this host and relegated subordinates to $H$. crispa. We conclude that competitive exclusion drives habitat segregation among life stages of this anemonefish and that host anemone traits underlie this process. The non-preferred host $H$. crispa may function as a refuge for juvenile fish while they wait for space to become available in the preferred host E. quadricolor, where they are able to attain sexual maturity.

KEY WORDS: Intraspecific competition · Symbiosis · Amphiprion bicinctus . Entacmaea quadricolor . Heteractis crispa $\cdot$ Coral reef

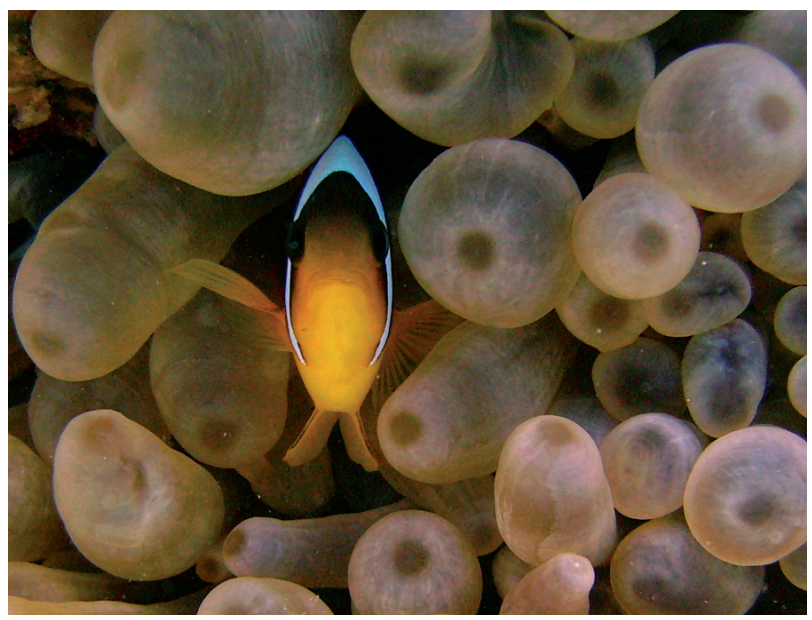

The tentacles of the sea anemone Entacmaea quadricolor offer optimal cover for anemonefish Amphiprion bicinctus.

Photo: L. K. Huebner

\section{INTRODUCTION}

Habitat segregation occurs between juvenile and adult life stages in many organisms, due in part to different habitat requirements at each life stage. In marine fishes, nursery habitats such as seagrass meadows often provide special conditions that support the growth and survival of juveniles, which then migrate to adult habitats for breeding (Beck et al. 2001). Habitat segregation among life stages also may result from active exclusion of juveniles from optimal habitat by adults. The processes of habitat preference, competition, and predation all affect patterns of habitat use among coral reef fishes, with 
important implications for their population dynamics (Holbrook \& Schmitt 2002, Dirnwöber \& Herler 2007 , Ben-Tzvi et al. 2009, Bonin et al. 2009). Many reef fishes behave aggressively toward conspecifics, with larger individuals maintaining dominance over smaller ones (Forrester et al. 2006), and denying access to benthic habitats for juveniles as they recruit to the reef from the plankton (Bay et al. 2001, Ben-Tzvi et al. 2009). Among reef fishes that form obligate symbioses with benthic cnidarians, the cnidarian hosts are a limiting resource for the population growth of their fish associates (Allen 1972, Holbrook et al. 2000). Coral characteristics such as body size, morphology, health, and surrounding habitat all can affect selection and preference for them as hosts by coral-dwelling gobies and damselfishes (Holbrook et al. 2000, Schiemer et al. 2009). Especially among damselfishes (Family Pomacentridae), patterns of coral habitat use are frequently altered by aggression among individuals for coral occupancy (Robertson 1996, Bay et al. 2001, Ben-Tzvi et al. 2009, Bonin et al. 2009).

Anemonefishes comprise 28 species of damselfishes that engage in obligate shelter symbioses with 10 species of sea anemones on Indo-Pacific coral reefs (Elliott et al. 1999). They are protandrous and form social groups with rigid size-based hierarchies in each host anemone: the terminal female is largest in size and dominant, her mate is second in size and rank, and any other individuals are smaller subadults or juveniles (e.g. Fautin 1991, Buston 2004). Depending on host size and anemonefish species, members of the breeding pair may not tolerate the presence of other group members, and will regularly evict juveniles that attempt to immigrate or recruit from the planktonic larval phase into their anemones (Buston 2003a). Because anemonefishes are more diverse than are host anemones, some anemone species host $>1$ anemonefish species, but many anemonefish also may associate with $>1$ host species (Fautin 1991). However, some hosts appear to be more desirable than others, resulting in potential monopolization by competitively dominant individuals (Fautin 1986). Thus, breeding pairs of adult fish may defend certain types of anemones, while conspecific juvenile fish are relegated to other types of host anemones (Fautin 1991, Chadwick \& Arvedlund 2005). However, the contributing factors and demographic impacts of this habitat segregation among anemonefish life stages are not well understood.

Anemonefishes provide an array of benefits to sea anemones: they protect them from predation by butterflyfishes (Porat \& Chadwick-Furman 2004), con- tribute nutrients to both the anemones and their endosymbiotic microalgae (Cleveland et al. 2011), and aerate host anemone tissues (Szczebak 2011). Anemones thus experience faster growth, higher survival, and enhanced asexual reproduction when hosting anemonefish (Holbrook \& Schmitt 2005). Additionally, anemones expand more fully when occupied by anemonefish than when alone, and, if their fish are removed, they may contract completely-despite minimized photosynthesis by their microalgae in such a state-until the anemonefish have returned (Porat \& Chadwick-Furman 2004). In contrast, the only documented benefit provided by sea anemones to anemonefishes is shelter from predation, to both the fish and their egg masses (Fautin 1991). Sea anemones vary in their traits that relate to sheltering fish, for example in terms of their chemical defenses (Elliott et al. 1994), tentacle morphology (Fautin \& Allen 1997), types of microhabitats occupied (Chadwick \& Arvedlund 2005), and in the provision of nearby substratum for the incubation of fish egg clutches (Allen 1972). Anemonefishes potentially compete for preferred host species based on these factors, causing their distributional patterns to differ from those expected based on host and fish abundances alone (Srinivasan et al. 1999). No studies to date have quantified variation among anemone species in their morphological or behavioral traits that affect their abilities to shelter anemonefishes, or determined the resulting impacts on anemonefish population dynamics.

In the Gulf of Aqaba, northern Red Sea, endemic 2-band anemonefish Amphiprion bicinctus mainly occupy bulb-tentacle sea anemones Entacmaea quadricolor and leathery sea anemones Heteractis crispa (Chadwick \& Arvedlund 2005). H. crispa are solitary with long, thin tentacles, and mainly host juveniles of $A$. bicinctus (Fishelson 1970, Chadwick \& Arvedlund 2005), while E. quadricolor possess thicker tentacles that may be long and digitiform or short and bulbous (Dunn 1981). Polyps of E. quadricolor replicate clonally to form aggregations in some parts of the Indo-Pacific (Fautin \& Allen 1997); however, only solitary individuals occur in the northern Red Sea, where they primarily host adult breeding pairs of fish, as well as occasional juveniles (Fishelson 1970, Chadwick \& Arvedlund 2005). Thus, habitat partitioning occurs among life stages of this anemonefish, in which individuals recruit to $H$. crispa but do not breed there. Additionally, these 2 host anemone species both usually occur in habitats which offer adjacent hard substrate for anemonefish to lay their egg masses: H. crispa often occur along 
the reef-sand interface and E. quadricolor occur along the reef-sand interface or are completely surrounded by reef rock (Chadwick \& Arvedlund 2005, authors' pers. obs.). Fish preferences for these hosts likely occur in large part due to host behavior and morphology, rather than host microhabitat use per se.

Here we examine 2 major hypotheses concerning anemonefish habitat segregation in this system: (1) the 2 host anemone species differ in their morphological and behavioral traits related to sheltering anemonefish and (2) aggressive interactions among life stages of this anemonefish determine their patterns of habitat segregation between the 2 host species. To test these hypotheses, we performed observations and experiments on coral reefs in the northern Red Sea, as well as experiments under controlled laboratory conditions at Auburn University.

\section{MATERIALS AND METHODS}

\section{Field surveys}

Fish and anemone population structure

We conducted field surveys in the Gulf of Aqaba, northern Red Sea, on coral reefs adjacent to the Marine Science Station (MSS), Aqaba, Jordan. Reef types in this area included patch reefs on sand flats and fringing reefs with steep reef slopes (Mergner \& Schuhmacher 1974, Khalaf et al. 2006). Amphiprion bicinctus (hereafter termed 'fish') reach $14 \mathrm{~cm}$ maximum total length (TL) and can begin to develop gonads at $6 \mathrm{~cm}$ TL (Fricke 1983), so we defined adults as $\geq 6 \mathrm{~cm}$ TL. The only other anemone-associated damselfish in the northern Red Sea, 3-spot dascyllus Dascyllus trimaculatus, were rare in this area (present in $<5 \%$ of anemones) and were not considered here.

To determine patterns of occupancy by juvenile and adult fish in the sea anemones Heteractis crispa and Entacmaea quadricolor (Fig. 1) and to quantify anemone body sizes, we conducted annual population censuses during June 2008, 2009, and 2010 at a marked study site near the MSS. This site was $\sim 1021 \mathrm{~m}^{2}$ on the reef slope at 6 to $16 \mathrm{~m}$ depth $(\sim 65 \mathrm{~m}$ along the slope parallel to shore $\times \sim 20 \mathrm{~m}$ down the slope perpendicular to shore) and was selected because it contained about 40 to 60 ind. of each host anemone species, which are adequate sample sizes for demographic analyses of anemone and fish populations (Chadwick \& Arvedlund 2005). Each host anemone within the site was marked with an engraved aluminum tag fixed by zip-tie to nearby dead reef substratum (after Porat \& ChadwickFurman 2004). During all 3 census years, body size (tentacle crown long and short diameter, to calculate tentacle crown surface area, TCSA; after Hattori 2002) and the number and TL of resident fish were recorded for all anemones at the site. Some anemones occurred near (<0.5 m distant) other anemones, and their associated fish moved between, and sheltered in, both hosts. To simplify the assessment of host use patterns, we excluded these adjacent anemones and fish from analyses ( 10\% of anemones censused).

We grouped anemones as hosting either no fish, juveniles only, or adult fish both with and without juveniles, and compared proportions of anemones in each species that hosted each fish grouping during each year using chi-squared tests. We did not compare these groups among years to avoid pseudoreplication. We determined differences in body size between anemone species using Mann-Whitney $U$ tests (data not normal after transformation). For each type of fish group, we applied $t$-tests to normalized (ln-transformed) data to compare host body size between the anemone species. We also performed ANOVAs to assess variation in anemone species body size with fish group: 3 groups for Heteractis crispa (ln-transformed) and 4 for Entacmaea quadriColor, because enough individuals of E. quadricolor hosted either 1 or 2 adult fish to separate them into different groups.

Anemone morphology and fish concealment

To determine how fish occupancy varied with host morphology, in June 2010 we compared patterns of abundance, body size, and associated fish between 2 morphotypes of Entacmaea quadricolor. We classified the tentacle morphology of most individuals at the study site $(\mathrm{N}=52$ of 58 anemones; we were unable to clearly determine morphotype for 6 anemones) as either bulbous (tentacles with pronounced bulbs near the tips, EQB; Fig. 1B) or digitiform (tentacles without bulbs, EQD; Fig. 1C), based on the shapes of most of their tentacles (Dunn 1981). We analyzed variation in the distribution of no fish, juveniles, or adult fish (with or without juveniles) between these anemone morphotypes using chi-squared tests. The body sizes of Heteractis crispa, EQB, and EQD anemones were compared using ANOVA. $T$-tests were used to compare the sizes of $H$. crispa and EQB with no fish and juvenile fish (there were too few EQD in these fish classes to include in analy- 

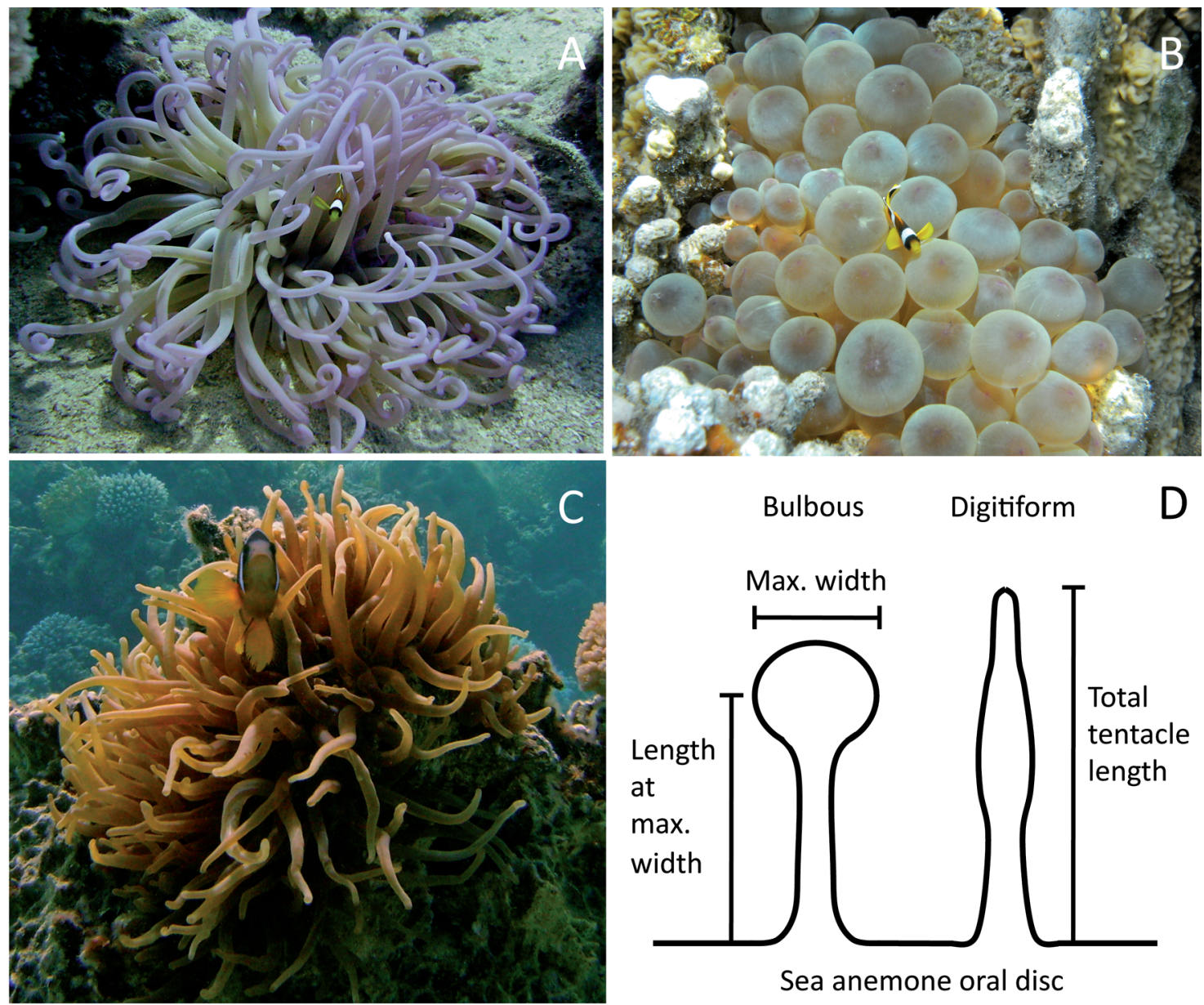

Sea anemone oral disc

Fig. 1. Study species and sea anemone tentacle morphology parameters on coral reefs at Aqaba, northern Red Sea: (A) leathery anemone Heteractis crispa, (B) bulbous morph of the bulb-tentacle anemone Entacmaea quadricolor, (C) digitiform morph of E. quadricolor, and (D) anemone tentacle shapes and the 3 morphological parameters measured on the tentacles: length, maximum width, and length at maximum width. Juvenile anemonefish Amphiprion bicinctus ( 1 to $2 \mathrm{~cm}$ total length [TL]) are visible in Panels A \& B, and an adult A. bicinctus ( 12 cm TL), in Panel C. Photographs by L. K. Huebner (A, C) and B. Dailey (B)

ses), and ANOVA was used to compare the sizes of all 3 morphotypes that contained adult fish. All morphotype size data were ln-transformed.

We quantified variation in tentacle morphology (Fig. 1D) among a subset of randomly selected EQB $(\mathrm{N}=11), \mathrm{EQD}(\mathrm{N}=10)$, and Heteractis crispa $(\mathrm{N}=$ 10). On each anemone, we haphazardly selected 10 tentacles, and measured tentacle length, maximum width, and length along the tentacle (from the base) where maximum width occurred. From these measurements, we calculated tentacle length at maximum width as a proportion of total tentacle length. All measurements were made with calipers placed near but not touching each anemone, to avoid tentacle contraction. Data on each of these 4 anemone tentacle characteristics were averaged among the 10 tentacles sampled per anemone to obtain a mean value of each characteristic per anemone. Then we applied ANOVAs to assess variation in each characteristic among the 3 anemone types.

We also determined variation in the abilities of juvenile and adult fish to conceal themselves among the tentacles of anemones that differed in morphology. We haphazardly selected anemones belonging to each of the 3 types until we obtained sufficient sample sizes of both juvenile and adult fish in each anemone type $(\mathrm{N} \geq 13$ for each of 5 fish-anemone combinations, excluding juvenile fish in EQD, which were rare). To quantify concealment, we chased fish into their host anemones, observed them as they attempted to hide among the tentacles, and recorded this process from directly above the anemone oral disc for 30 to 60 s using a Canon PowerShot 1200IS digital camera. Using QuickTime ${ }^{\circledR}$, we paused each 
video at the frame where the fish was maximally concealed among the tentacles of its anemone. We then categorized the concealment of each fish as either 0 to $50 \%$ or 51 to $100 \%$ covered by the anemone tentacles and compared the percent body concealment of juvenile versus adult fish in each of the 3 anemone types using chi-squared tests.

\section{Experiments on host preference}

\section{Field}

To assess fish preference for hosts, we conducted field experiments outside the census site in which we manipulated fish in heterospecific pairs of adjacent anemones (1 ind. each of Entacmaea quadricolor and Heteractis crispa $<2 \mathrm{~m}$ apart, hereafter 'anemone pair'). These pairs were chosen because they were close enough together for fish to move between each anemone (Hattori 1994), and thus exhibit preference between hosts. In 2009, we marked 12 anemone pairs at 2 to $11 \mathrm{~m}$ depth with aluminum tags, and in each pair removed all fish from one anemone (6 removals from E. quadricolor and H. crispa each). We observed each pair daily, and recorded the first movements of fish between paired anemones, body sizes of fish that moved, and anemones occupied at the end of the experiment $(8 \mathrm{~d})$.

In 2010, we conducted a more extensive experiment in which we haphazardly selected and mapped (as described above) 18 anemone pairs at 2 to $9 \mathrm{~m}$ depth (different from those in 2009). We collected census data on all anemones and fish within a $5 \mathrm{~m}$ radius around each anemone in the pair and recorded identifying marks (e.g. shapes of white bands) on all fish, to assess individual fish movements. We randomly selected 6 pairs for fish removal from Heteractis crispa, 6 for fish removal from Entacmaea quadricolor, and 6 as control pairs with no fish removal. We collected fish using hand nets and transported them in plastic bags to flow-through aquaria at the MSS, where they were fed daily. At the end of the experiment, about half of these fish were returned to vacant anemones on the reef and the remaining fish were moved to the MSS public aquarium.

After fish removals, we monitored anemones for 30 min to assess immediate movement among hosts by the remaining nearby fish. Then each day for up to $13 \mathrm{~d}$ we recorded anemone TCSA and condition (pale, contracted, tentacle morphology, etc.), resident fish size and identity, species of original host anemone for each migrating fish, and distances traveled to colonize new hosts. We combined data between years to assess proportions of occupied versus vacant anemones at the end of the experiment and the number of fish moved to each anemone species. These data were compared using chi-squared tests, as were the number of juvenile versus adult fish that moved among anemones in 2010. We applied a $t$-test to determine variation between anemone species in the time from resident fish removal to immigration of new fish for both years. Variation in re-expansion behavior of anemones between the day before receiving a fish immigrant and the day afterward was determined with a paired $t$-test (2010 only).

In 2010, during fish capture, we observed that anemones often contracted when touched by hand nets and that re-expansion depended on fish presence. To quantify this, immediately before fish removal we measured TCSA on 6 anemones of each species from which we removed the fish and 6 from which we did not remove all fish. Then we manually disturbed each anemone by shaking a hand among the tentacles until contraction ceased $(\sim 10 \mathrm{~s})$ and immediately re-measured anemone TCSA $(\mathrm{N}=23$ anemones measured for contracted size; no data for 1 Entacmaea quadricolor removal). Percent change in TCSA of each species in response to this disturbance was compared with a $t$-test. We measured the TCSA of these anemones each day for $2 \mathrm{~d}$ following disturbance, to compare re-expansion rates of anemones with versus without fish. Fish were allowed to recolonize the anemones at will, so the sample size of E. quadricolor without fish decreased from 6 before disturbance to 5 immediately afterwards, then 4 after $1 \mathrm{~d}$, and 3 after $2 \mathrm{~d}$, precluding statistical comparisons among treatment groups.

\section{Laboratory}

To assess host choice by fish under controlled conditions, we performed laboratory experiments at Auburn University during 2010 and 2011 using laboratory-reared Amphiprion bicinctus (culture conditions in Roopin \& Chadwick 2009). All fish $(\mathrm{N}=27)$ were pre-reproductive (either juveniles or larger fish not yet in breeding pairs; $5.6 \pm 2.1 \mathrm{~cm}$ TL, range: 1.5 to $9.8 \mathrm{~cm}$ ) to control for variation in host preference with fish reproductive status. To control for effects of previous exposure to anemones in laboratory aquaria, each fish was subjected to a pre-experimental treatment of placement alone in an aquarium with 1 Entacmaea quadricolor and 1 Heteractis crispa directly adjacent to each other. The fish remained in this 
aquarium for $4 \mathrm{~h}$, during which time it contacted both anemones and then was removed and isolated in an aquarium with no anemones for $48 \mathrm{~h}$. Preliminary observations indicated that this procedure eliminated any initial preference by fish for the anemone species with which they had most recently been cultured. During a pilot study, we discovered that fish previously kept with one anemone species showed an initial preference for that species. However, when these fish were exposed to both anemone species as above, and then isolated from all anemones for a period of at least $36 \mathrm{hr}$, they did not exhibit a preference for the anemone species with which they had most recently been cultured, but instead behaved as fish that had never been exposed to an anemone.

We conducted host selection experiments in 751 laboratory aquaria $(\sim 75 \times 30 \times 30 \mathrm{~cm})$ with $\sim 2 \mathrm{~cm}$ of a crushed coral-gravel substratum. Each aquarium was marked lengthwise into 6 equal sections along the rear glass wall to facilitate monitoring of fish positions (after Arvedlund \& Nielsen 1996). A sidemounted carbon power filter and a water heater near the center of the aquarium maintained uniform water circulation and temperature. For experimental trials, a single Entacmaea quadricolor was placed at one randomly selected end of the aquarium (Section 1), and a single Heteractis crispa of approximately the same size was placed at the other end (Section 6; range of anemone TCSAs: 30.6 to $99.3 \mathrm{~cm}^{2}$; trials with the smallest fish used the smallest anemones). Both anemones were measured before and after each trial to ensure that they remained fully expanded and approximately the same size; if not, the trial was discarded. Fish were placed in a mesh cylinder in the center of the aquarium, equidistant from both anemones (after Bollinger et al. 2008), enabling them to see and smell both anemones while acclimating to the aquarium and allowing the anemones to expand fully for at least $1 \mathrm{~h}$ before the start of each behavioral trial. Then the mesh chamber was slowly removed, and the position of the fish was recorded by section every $30 \mathrm{~s}$ for $1 \mathrm{~h}$ (after Arvedlund \& Nielsen 1996). A blind prevented fish from seeing the observer.

Host selection was determined in 3 treatments in which fish were either solitary, dominant, or subordinate. Dominance was determined by body size, with dominant fish being 0.75 to $1.5 \mathrm{~cm}$ TL larger than subordinate fish, which is the size difference between fish of adjacent social ranking in the congener Amphiprion percula (Buston 2003b). Host selection by a dominant fish was established first through a solitary trial, and then a subordinate fish was added to the center of the aquarium in the mesh cylinder and allowed to acclimate as described above. This procedure mimicked natural processes on coral reefs, in which smaller anemonefish attempt to gain residency in anemones that already host larger fish (Buston 2003a). Controls for the effect of aquarium shape on fish location also were performed using the methods above, except that no anemones were present in the aquarium. We performed trials on 20 solitary, 19 dominant, and 20 subordinate fish in both experimental and control scenarios. Due to a limited stock of laboratory fish, some of the 27 fish were used more than once: 15 and 17 fish were exposed to all 3 treatments, and 9 and 6 fish to only some treatments, in the experimental and control scenarios, respectively. No fish were repeated within each treatment, and we did not statistically compare trials that used the same fish (e.g. Srinivasan et al. 1999). After each treatment, the anemones were removed from the tank, the substratum was thoroughly mixed, and $50 \%$ of the water was changed to ensure that minimal anemone scents remained in the aquarium. Carbon filters were replaced every eighth trial. We employed Wilcoxon signed-rank tests to assess whether fish distribution in the aquaria within each treatment was random, or deviated from a hypothetical median (i.e. the center of the aquarium; after Arvedlund et al. 1999). All results are presented as mean $( \pm \mathrm{SD})$ unless otherwise noted.

\section{RESULTS}

\section{Field surveys}

Fish and anemone population structure

During all $3 \mathrm{yr}$, the proportions of sea anemones that hosted no fish, juveniles, or adult fish differed significantly between the 2 host species $\left(\chi^{2}=21.975\right.$, df $=2, \mathrm{p}<0.001$ in $2008, \chi^{2}=7.729$, df $=2, \mathrm{p}=0.021$ in 2009, and $\chi^{2}=31.862$, df $=2, \mathrm{p}<0.001$ in 2010). Juvenile fish associated significantly more frequently with Heteractis crispa than they did with Entacmaea quadricolor, which hosted significantly more adult fish, both per individual anemone and per unit area of anemone tentacle crown (Table 1, Fig. 2). Although $H$. crispa were slightly less abundant than $E$. quadricolor, they provided only about half as much tentacle crown surface area as did E. quadricolor (Table 1), because they were significantly smaller during 2 of the 3 yr examined (Mann-Whitney tests: $U_{1}=1255, \mathrm{p}=0.492$ for $2008, U_{1}=1291.5, \mathrm{p}=0.004$ 
Table 1. Abundances of juvenile and adult anemonefish Amphiprion bicinctus and of host sea anemones Heteractis crispa and Entacmaea quadricolor on a $1021 \mathrm{~m}^{2}$ coral reef site at Aqaba, northern Red Sea. The total tentacle crown surface area (TCSA) of each anemone species, and fish abundance per TCSA, are shown. N: sample size of anemones

\begin{tabular}{|c|c|c|c|c|c|c|c|c|}
\hline \multirow[t]{2}{*}{ Anemone } & \multirow[t]{2}{*}{$\mathrm{N}$} & \multirow{2}{*}{$\begin{array}{c}\mathrm{N} \text { per } \\
10 \mathrm{~m}^{2} \text { site }\end{array}$} & \multirow{2}{*}{$\begin{array}{c}\text { Total TCSA } \\
\left(\mathrm{m}^{2}\right)\end{array}$} & \multirow{2}{*}{$\begin{array}{c}\text { TCSA } \\
\text { (\% site area) }\end{array}$} & \multicolumn{2}{|c|}{ No. of $A$. bicinctus } & \multicolumn{2}{|c|}{ Density of $A$. bicinctus (no. per $\mathrm{m}^{2}$ total TCSA) } \\
\hline & & & & & Juvenile & Adult & Juvenile & Adult \\
\hline \multicolumn{9}{|l|}{2008} \\
\hline H. crispa & 40 & 0.39 & 12.67 & 1.24 & 22 & 8 & 1.7 & 0.6 \\
\hline E. quadricolor & \multirow{2}{*}{\multicolumn{8}{|c|}{$\chi^{2}=29.90, \mathrm{df}=1, \mathrm{p}<0.001$}} \\
\hline & & & & & & & & \\
\hline 2009 & & & & & & & & \\
\hline H. crispa & 38 & 0.37 & 5.85 & 0.57 & 14 & 11 & 2.4 & 1.9 \\
\hline \multirow[t]{2}{*}{ E. quadricolor } & 50 & 0.49 & 14.18 & 1.39 & 16 & 36 & 1.1 & 2.5 \\
\hline & \multicolumn{8}{|c|}{$\chi^{2}=4.52, \mathrm{df}=1, \mathrm{p}<0.05$} \\
\hline \multicolumn{9}{|l|}{2010} \\
\hline H. crispa & 53 & 0.52 & 10.83 & 1.06 & 24 & 8 & 2.2 & 0.7 \\
\hline E. quadricolor & 58 & 0.57 & 20.22 & 1.98 & 11 & 52 & 0.5 & 2.6 \\
\hline & \multicolumn{8}{|c|}{$\chi^{2}=30.20, \mathrm{df}=1, \mathrm{p}<0.001$} \\
\hline
\end{tabular}

for 2009, and $U_{1}=1930.5, \mathrm{p}=0.020$ for 2010; Fig. 3). The 2 anemone species did not vary significantly in body size according to the life stage of their resident fish ( $t$-tests, $\mathrm{p}>0.05$ ), except for hosts of juvenile fish in 2008, where H. crispa were larger than E. quadricolor $\left(t_{21}=-2.378, \mathrm{p}=0.027\right)$, and hosts of adult fish in 2009, where E. quadricolor were larger than $H$. crispa $\left(t_{31}=2.996, \mathrm{p}=0.005\right.$; Fig. 3$)$. In all $3 \mathrm{yr}$, the body sizes of $H$. crispa did not vary significantly with the life stage of resident fish (ANOVAs, p > 0.05), but the body sizes of E. quadricolor did $\left(F_{3,54}=7.274, \mathrm{p}<\right.$ 0.001 in 2008, $F_{3,46}=8.950, \mathrm{p}<0.001$ in 2009, and $F_{3,54}=5.571, \mathrm{p}=0.002$ in 2010): those that hosted 2 adult fish were significantly larger than those with 1 adult fish, only juveniles, or no fish at all, which were similar to each other in body size (Tukey's honestly significant difference [HSD]: $p<0.05$ for all comparisons of anemones with 2 adult fish to anemones with other fish life stages, except in 2008, where $\mathrm{p}=0.051$ for anemones with 2 adult fish compared to anemones with 1 adult fish; Fig. 3).

\section{Anemone morphology and fish concealment}

EQB anemones $(\mathrm{N}=31)$ were more abundant than EQD anemones $(\mathrm{N}=21)$, and together were about equal in abundance to Heteractis crispa $(\mathrm{N}=53$; Fig. 4). EQD anemones usually hosted 1 to 2 adult fish, while EQB anemones sometimes contained either 1 adult or no fish at all, but this difference was not significant $\left(\chi^{2}=5.526\right.$, df $\left.=2, p=0.063\right)$. EQD anemones had significantly larger tentacle crowns than did either EQB anemones or $H$. crispa, which did not differ in tentacle crown size from each other
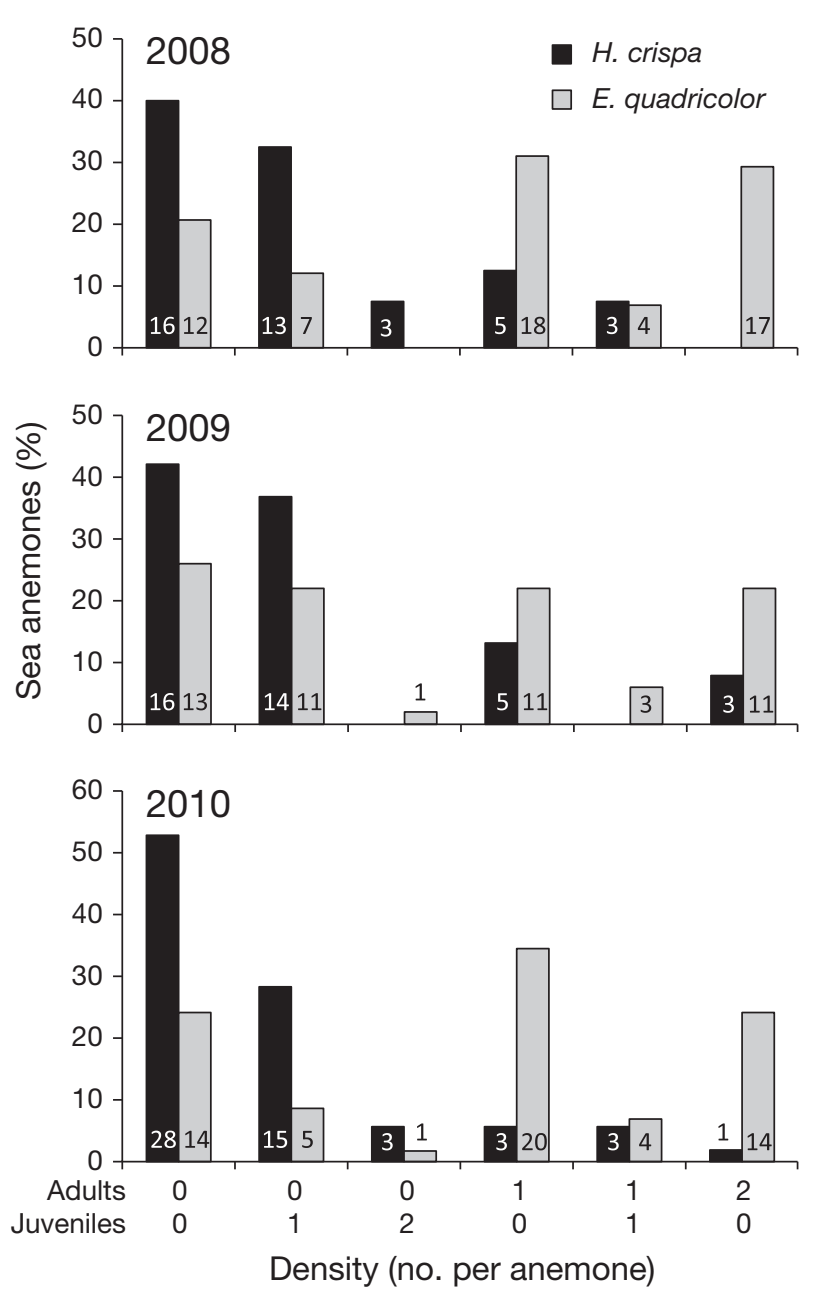

Fig. 2. Distributions of juvenile and adult anemonefish Amphiprion bicinctus in sea anemone hosts Heteractis crispa and Entacmaea quadricolor during $3 \mathrm{yr}$ on coral reefs at Aqaba, northern Red Sea. Sample sizes of anemones are at the base of each column 

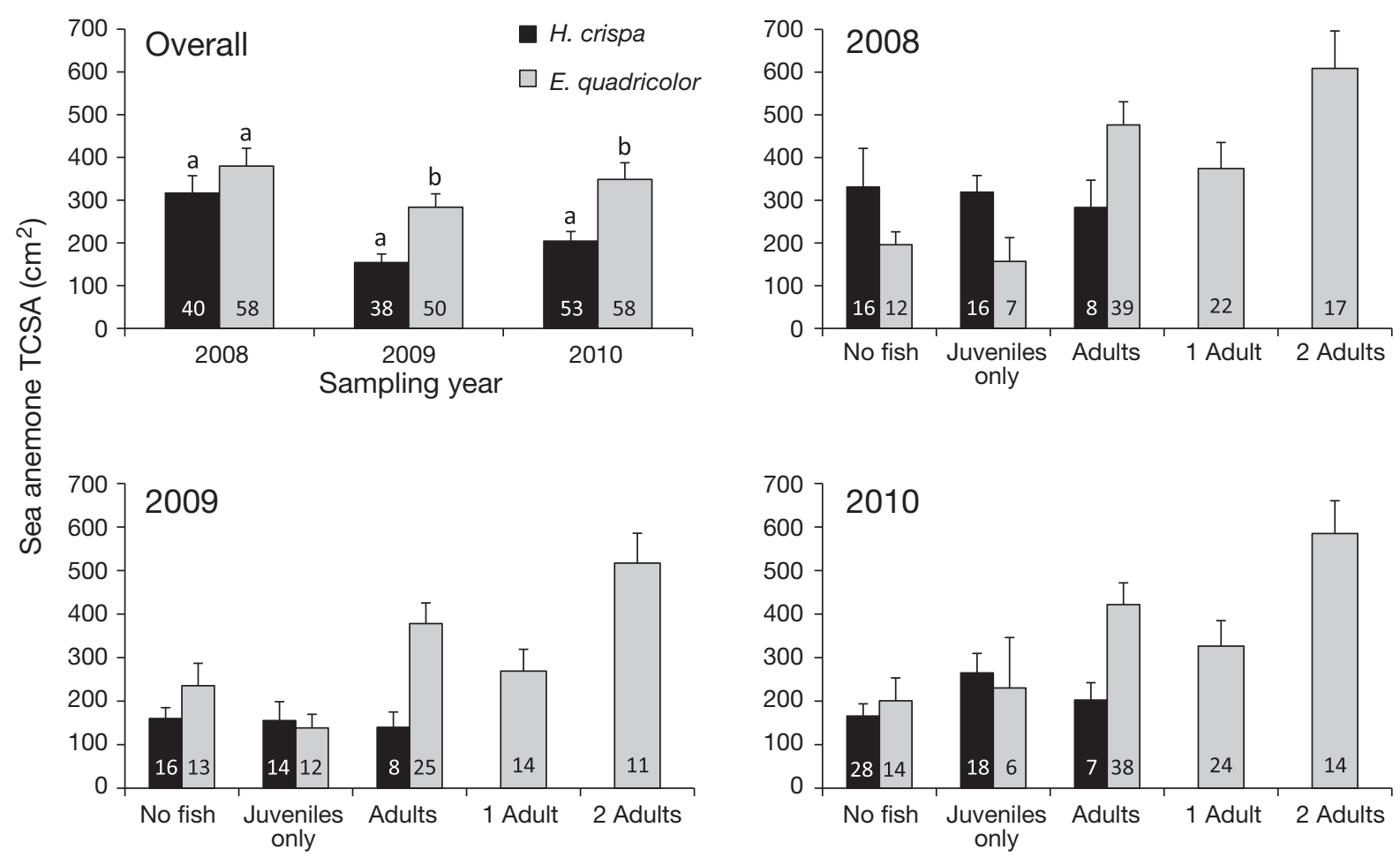

Life stage of resident $A$. bicinctus

Fig. 3. Variation in body size between sea anemones Heteractis crispa and Entacmaea quadricolor with life stage of anemonefish residents Amphiprion bicinctus among 3 yr on coral reefs at Aqaba, northern Red Sea. Significant differences in overall body size between the 2 anemone species are shown with letters. Statistical results of anemone size comparisons by life stage of fish residents are in 'Results - Field surveys of fish and anemone population structure'. Data are mean \pm SE. Sample sizes of anemones are at the base of each column. TCSA: tentacle crown surface area

(ANOVA: $F_{2,102}=14.075, \mathrm{p}<0.001$; Tukey's HSD: $\mathrm{p}<$ 0.001; Fig. 4). EQD anemones that hosted adult fish also were significantly larger than the other 2 host types, which did not differ from one another (ANOVA: $F_{2,42}=16.924, \mathrm{p}<0.001$; Tukey's HSD: $\mathrm{p} \leq 0.002$ ). Finally, H. crispa and EQB anemones that hosted no fish or only juveniles did not differ significantly in body size from each other ( $t$-tests: $t_{34}=0.448, \mathrm{p}=$ 0.657 for no fish and $t_{20}=0.443, \mathrm{p}=0.622$ for juvenile fish; Fig. 4).

All 4 tentacle parameters differed significantly among the 3 morphological types of host anemones (ANOVAs; Fig. 4): total tentacle length $\left(F_{2,28}=\right.$ 17.791, $\mathrm{p}<0.001)$, maximum tentacle width $\left(F_{2,28}=\right.$ $39.032, \mathrm{p}<0.001)$, tentacle length at maximum width (ln-transformed, $F_{2,28}=23.761, \mathrm{p}<0.001$ ), and percent tentacle length at maximum width $\left(F_{2,28}=73.128, \mathrm{p}<\right.$ 0.001). They also differed significantly for all Tukey's HSD among the 3 morphological host types $(\mathrm{p}<$ $0.05)$, except in terms of total tentacle length between Heteractis crispa and EQD ( $p=0.928)$, and tentacle length at maximum width between EQB and EQD $(p=0.184)$. EQB anemones possessed much shorter and wider tentacles than did either H. crispa or EQD anemones, and the widest parts of their tentacles were the most terminally located (Fig. 4).

Juvenile and adult fish varied significantly in their abilities to conceal themselves among the tentacles of the 3 morphotypes of host anemones: juvenile fish concealed themselves equally well ( $>50 \%$ of body surface area) among the tentacles of both Heteractis crispa (87.5\% of $\mathrm{N}=16$ fish) and EQB anemones $\left(100 \%\right.$ of $\mathrm{N}=14 \mathrm{fish}_{i} \chi^{2}=1.875, \mathrm{df}=1, \mathrm{p}=0.171$; they rarely occurred in EQD anemones), but the ability of adult fish to conceal themselves varied significantly among the 3 anemone types $\left(\chi^{2}=24.588\right.$, df $=2, p<$ 0.001 ). Most adult fish concealed $\leq 50 \%$ of their body surface area in $H$. crispa ( $84.6 \%$ of $\mathrm{N}=13$ fish), but concealed $>50 \%$ of their body surface area in both EQB $(100 \%$ of $\mathrm{N}=16$ fish) and EQD $(78.6 \%$ of $\mathrm{N}=14$ fish) anemones. Thus, juvenile fish hid equally well among the tentacles of both anemone types in which they commonly occurred (H. crispa and EQB), but adult fish hid less well among the tentacles of $H$. crispa than among those of both Entacmaea quadricolor morphotypes. 

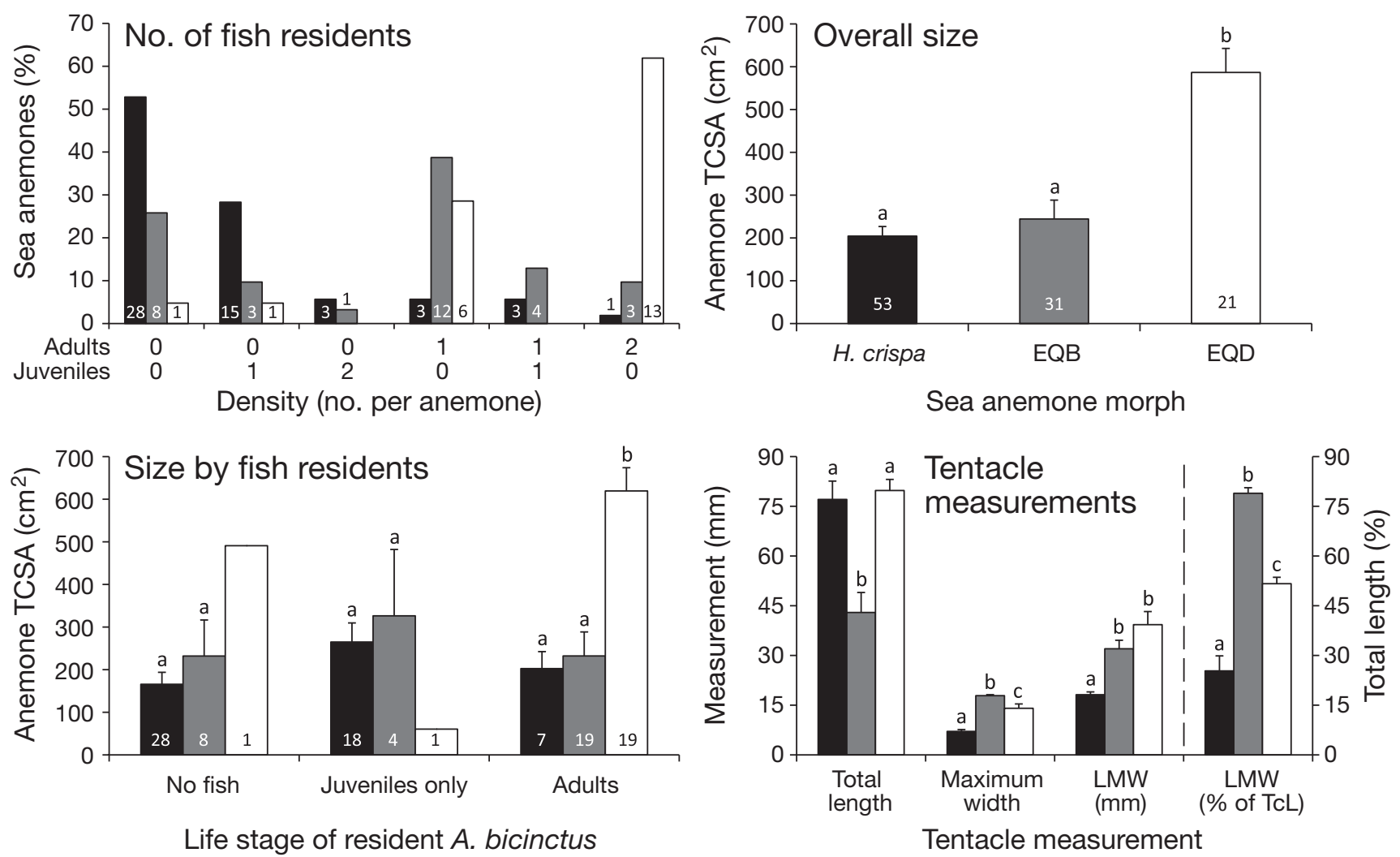

Fig. 4. Variation among 3 morphological types of sea anemones, Heteractis crispa (black), bulbous morphotype of Entacmaea quadricolor (EQB, grey), and digitiform morphotype of E. quadricolor (EQD, white) in the distribution of associated adult and juvenile anemonefish Amphiprion bicinctus, overall anemone body size, body size by life stage of fish residents, and tentacle morphology, on coral reefs at Aqaba, northern Red Sea in 2010. The fish and size data for H. crispa are the same as in Figs. 2 \& 3 , but are shown here for comparison with those of the 2 morphotypes of $E$. quadricolor. Letters indicate significant differences within column clusters. Data on tentacle length at maximum width (LMW) were ln-transformed for statistical analyses, but original values are shown for comparison. LMW data are also shown as a percentage of total tentacle length (TcL). Data are mean \pm SE. Sample sizes of anemones are at the base of each column

\section{Experiments on host preference}

Field

Patterns of fish migration to vacated anemones varied significantly between the 2 host species $\left(\chi^{2}=\right.$ 16.667, df $=1, \mathrm{p}<0.001)$. Of the 12 Heteractis crispa from which we removed fish, only 1 was re-occupied by a fish in $13 \mathrm{~d}$ of observations, while almost all (11 of 12) vacated Entacmaea quadricolor were reoccupied by fish from nearby anemones ( $<5 \mathrm{~m}$ distant). In addition, 1 newly metamorphosed fish $(<1 \mathrm{~cm}$ TL) recruited into the remaining empty E. quadricolor (resulting in 100\% occupancy for this host), and 3 newly metamorphosed fish recruited into empty $H$. crispa (resulting in 33.33\% occupancy for this host, still significantly lower than for E. quadricolor: $\chi^{2}=$ 12.000, df $=1, \mathrm{p}=0.001)$. The single fish that migrated to $H$. crispa was a juvenile, and did so from another $H$. crispa located $5.5 \mathrm{~m}$ away. Although we did not observe movement among experimental anemones within the first $30 \mathrm{~min}$ post-removal, vacant E. quadricolor were colonized rapidly, within about $3 \mathrm{~d}(2.58 \pm 2.11 \mathrm{~d}, \mathrm{~N}=12$, range: 1 to $8 \mathrm{~d})$, while $H$. crispa were colonized more slowly ( $t$-test: $t_{22}=$ $-3.796, \mathrm{p}=0.001)$, after about $6 \mathrm{~d}(6.25 \pm 2.60 \mathrm{~d}, \mathrm{~N}=$ 12 , range: 2 to $11 \mathrm{~d}$ ) or more, because we conservatively assumed that vacant $H$. crispa were colonized as soon as our field observations ended. In the control anemone pairs, we did not observe any fish movement among anemones, or recruitment of fish from the plankton into the anemones, during the period of study (13 d).

On several occasions ( $\mathrm{N}=6)$, initial fish immigrants to recently vacated Entacmaea quadricolor were subsequently ousted by larger fish (within 1 to $5 \mathrm{~d}$ ) and forced to return to their original anemones. Thus, the initial migration event was the best indicator of fish 
host preference, while subsequent movements often resulted from aggressive interactions. More fish $(\mathrm{N}=$ 9) emigrated from Heteractis crispa than from $E$. quadricolor $(\mathrm{N}=6)$, and more of these fish migrated to E. quadricolor $(\mathrm{N}=14)$ than into $H$. crispa $(\mathrm{N}=1$; $\chi^{2}=9.600, \mathrm{df}=1, \mathrm{p}=0.002$ ), and during all interspecific migrations, fish switched from $H$. crispa to $E$. quadricolor $(\mathrm{N}=8)$.

During 2010, within 6 to 13 d post-removal, 11 of the 52 remaining fish $(21.15 \%)$ moved among mapped anemones. Of these $11 \mathrm{fish}, 10$ were adults $(8.8 \pm 2.2 \mathrm{~cm}$ TL, range: 5 to $13 \mathrm{~cm})$, comprising onethird of the remaining 30 adult fish in experimental anemones, a larger proportion than for the 1 of 22 remaining juvenile fish that moved $\left(\chi^{2}=4.700, \mathrm{df}=1\right.$, $\mathrm{p}=0.030) ; 4$ of the 10 moving adults emigrated from anemones that they shared with 0 or 1 juveniles, into anemones with larger adults, thereby decreasing in social rank but gaining a potential mate. One adult briefly cohabited a new anemone with a larger adult, then migrated to a vacant anemone nearby, and was therefore the only individual to increase in social rank by moving to a different host; this movement may have occurred due to aggression from the larger fish, which was also a new immigrant. No adult fish deserted an adult partner in their original, pre-experiment anemone to migrate to a new host; 4 of the 11 migrating fish moved twice or more: 4 subsequent movements were among Entacmaea quadricolor,

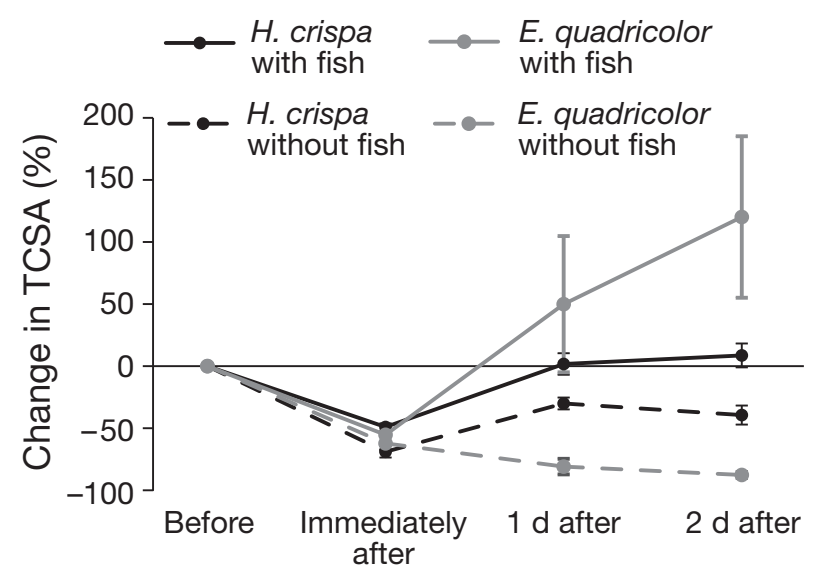

Time relative to manual disturbance

Fig. 5. Variation in the percent change in body size (tentacle crown surface area, TCSA), due to contraction and re-expansion after manual disturbance, of the host sea anemones Entacmaea quadricolor and Heteractis crispa, with and without anemonefish Amphiprion bicinctus, on coral reefs at Aqaba, northern Red Sea. Initially, $\mathrm{N}=6$ anemones were in each treatment; the number of empty E. quadricolor then decreased rapidly (see 'Results-Field experiments on host preference by fish' for details). Data are mean $\pm \mathrm{SE}$
1 was from Heteractis crispa to E. quadricolor, and 2 were from $E$. quadricolor to $H$. crispa, representing returns to original hosts. Overall, fish migrated $3.62 \pm$ $1.43 \mathrm{~m}$ within clusters of experimental anemones ( $\mathrm{N}$ $=9$ clusters, range of movements: 1.52 to $5.56 \mathrm{~m}$ ), but 2 adult fish (9 and $10 \mathrm{~cm} \mathrm{TL}$ ) were immigrants from outside these areas, $>6 \mathrm{~m}$ from the nearest mapped anemone (not included in distance calculations).

All individuals of both anemone species contracted immediately after manual disturbance (by $58.4 \pm$ $16.8 \%$ in 11 Entacmaea quadricolor and $59.0 \pm$ $14.4 \%$ in 12 Heteractis crispa), and contraction rates did not differ significantly with species ( $t$-test: $t_{21}=$ $-0.085, \mathrm{p}=0.933)$. However, E. quadricolor that still possessed fish expanded post-disturbance, some doubling their body sizes, but E. quadricolor from which fish had been removed shrank, and $H$. crispa did not change much in body size (Fig. 5). When fish migrated to contracted anemones of both species, they agitated the tentacles by swiftly moving and jerking among the tentacles and appeared to induce anemone expansion. All anemones of both species in the removal experiment expanded between the day before receiving a fish immigrant and the day afterwards (paired $t$-test: $t_{10}=-3.810, \mathrm{p}=0.003$ ). Most $E$. quadricolor that remained without fish contracted into reef holes and after several days their tentacles appeared paler and more bulbous than prior to fish removal, but the anemones did not contract out of sight or die during the 1 to $7 \mathrm{~d}$ they were observed without fish. H. crispa appeared to move their tentacles more often after their fish were removed than beforehand, and $1 \mathrm{H}$. crispa migrated $0.5 \mathrm{~m}$ from sandy to rocky habitat $3 \mathrm{~d}$ after its single fish was removed.

\section{Laboratory}

All 20 solitary fish spent significantly more of the 60 min observation period in contact with the tentacles of Entacmaea quadricolor (Fig. 6), and only rarely ventured to the Heteractis crispa at the opposite end of the aquarium. When a second, subordinate fish was introduced, 17 of the original, now dominant fish continued to associate significantly with E. quadricolor. However, 2 dominant fish aggressively excluded the subordinate fish from both anemones, swimming back and forth between the hosts, and causing their positions to be distributed randomly in the aquarium. This aggression caused 1 subordinate fish to exhibit a random distribution in the aquarium and 14 to 


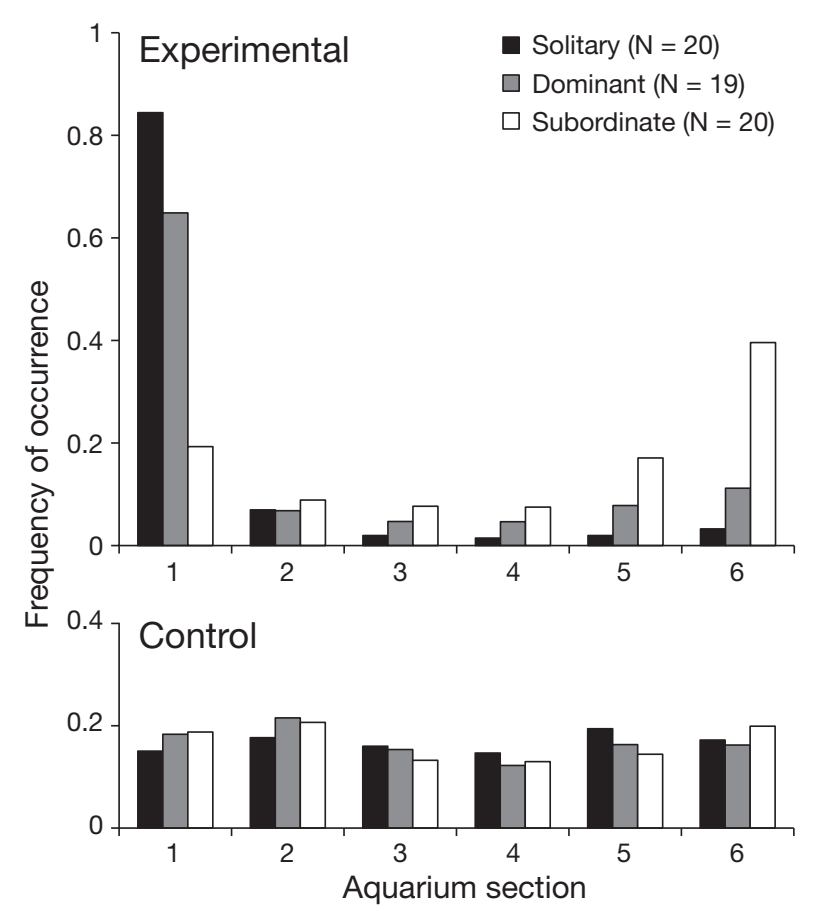

Fig. 6. Frequency of occurrence of anemonefish Amphiprion bicinctus in sections of laboratory experimental and control aquaria (no anemones) corresponding to the locations of host anemones. Shading indicates hierarchical status. In experimental trials, Section 1 corresponds to Entacmaea quadricolor and Section 6 corresponds to Heteractis crispa

associate with $H$. crispa. These 14 subordinate fish hovered in or near $H$. crispa and occasionally ventured toward E. quadricolor before being chased back to $H$. crispa. The remaining 5 subordinate fish were permitted in or near E. quadricolor by the dominant fish. In control trials with no anemones present, most fish in all social positions exhibited random distributions (14 solitary, 13 dominant, 13 subordinate), while some preferred one end of the aquarium (6 solitary, 6 dominant, 7 subordinate; Fig. 6).

\section{DISCUSSION}

We demonstrate here that 2-band anemonefish Amphiprion bicinctus at all post-settlement life stages prefer to associate with bulb-tentacle sea anemones Entacmaea quadricolor rather than with leathery sea anemones Heteractis crispa. Variation in morphological traits between the hosts appears to drive fish preference, especially the relatively large body size and thicker tentacles of E. quadricolor, among which adult anemonefish are better able to conceal themselves than among the thinner tentacles of $H$. crispa. Our field and laboratory experiments reveal that adult fish aggressively exclude juveniles from access to E. quadricolor, causing intraspecific competition that at least in part drives size-based patterns of habitat segregation by anemonefish between these 2 host species.

\section{Fish and anemone population structure}

The distribution of adult anemonefish in Entacmaea quadricolor and of juveniles or no fish in Heteractis crispa in Jordan is similar to patterns documented previously in nearby Israel and Egypt (Fishelson 1970, Chadwick \& Arvedlund 2005). This pattern also is similar to that of Gobiodon spp. gobies in the northern Red Sea, in which breeding pairs occupy preferred host coral species and non-breeders are relegated to sub-optimal hosts (Dirnwöber \& Herler 2007). We observed that pairs of juvenile anemonefish, or 1 juvenile paired with an adult, are uncommon in both anemone hosts, and hypothesize that these occupation patterns are rare because (1) two juvenile fish are unable to fend off adults from an anemone that is sufficiently large to accommodate the juveniles and (2) an adult fish alone may not tolerate the presence of a juvenile, instead preferring to remain alone with extra space available into which another adult may potentially migrate. Amphiprion bicinctus, like other anemonefishes (Fautin 1986, Hattori 1994), can utilize multiple anemones within a several meter radius 'home range', preferring a single, central anemone, but visiting others (Brolund et al. 2004). During our field surveys, we observed that some $A$. bicinctus utilize $>1$ E. quadricolor that are $>1 \mathrm{~m}$ apart, but when approached, the fish choose one anemone to retreat into and guard. Thus, the percent of 'empty' $E$. quadricolor with no fish (20 to $26 \%$ ) is likely an overestimate, as many of these probably are utilized by fish that retreated to another anemone during our census and were not recognized as being occupied. Because $A$. bicinctus are not poor swimmers and the density of hosts at our study site is high, $A$. bicinctus may move among hosts inside defended territories, in addition to occasionally venturing outside of their home territories. Adult fish territories may include both species of anemones even though they prefer E. quadricolor, and some small juveniles may live inside adult territories. Long-term observations on individual fish would more accurately reveal their habitat segregation based on spacing patterns of territorial and home range structure. 


\section{Anemone morphology and fish concealment}

Beyond the long-term size benefits known for some anemones from hosting anemonefish (Porat \& Chadwick-Furman 2004, Holbrook \& Schmitt 2005), our results reveal short-term benefits in terms of host expansion behavior. Some anemones expand more in the presence of fish symbionts (Porat \& ChadwickFurman 2004), and fish behaviors may cause this effect: new immigrant fish spend more time moving among and agitating the tentacles of hosts than do long-term residents. This stimulation of host expansion behavior provides benefits to both partners: more shelter for the anemonefish from predators and more tentacle surface area for photosynthesis by host microalgae (Porat \& Chadwick-Furman 2004). The activities of resident fish may stimulate full tentacle expansion in Entacmaea quadricolor, a host species that is especially dependent on anemonefishes for survival (Fautin 1986). Our observations that $E$. quadricolor which remained vacant for 1 to $2 \mathrm{~d}$ contracted into their reef holes and lost microalgal pigmentation until they received new fish residents supports this idea (Porat \& Chadwick-Furman 2004, 2005). In contrast, Heteractis crispa did not noticeably contract or bleach after anemonefish were removed, suggesting that they are potentially less dependent on fish as stimuli for short-term expansion. However, H. crispa are not entirely unaffected by fish removal, as they appeared to move their tentacles more often after fish were removed than before, similar to spontaneous tentacle retraction by laboratory anemones when kept without fish (Fukui 1973). The malleable body sizes of E. quadricolor in response to fish activity potentially contribute to fish preference for this host species. However, the less dramatic response of $H$. crispa to resident fish may result at least in part from the smaller body sizes of colonizing fish relative to $E$. quadricolor.

Fine-branched stony corals exhibit smaller distances and shallower crevices between their branches, and thus shelter more juvenile damselfish Dascyllus aruanus, than do coarse-branched corals, which have deeper crevices between branches and shelter more adult fish (Holbrook et al. 2000). Similarly, the fit between fish body shape and host tentacle shape impacts anemonefish sheltering ability. In Amphiprion bicinctus, the ratio of body standard length (SL) to body depth is about 1.8:1 to 1.9:1 (Allen 1972). As such, large adult $A$. bicinctus (9 cm SL; Brolund et al. 2004) have a body depth of about $4.7 \mathrm{~cm}$, which is greater than the tentacle length of EQB anemones; a fish with this body depth would protrude from among the tentacles instead of hiding under their tips. In contrast, juvenile and small adult fish (e.g. a 6 cm SL fish with $3.2 \mathrm{~cm}$ body depth), which are more common in EQB anemones, have a body depth less than total tentacle height, explaining why they are able to conceal themselves completely in anemones with this morphology. Finally, the large adult fish in pairs are most common in EQD anemones, where the tentacles are longer than their body depths, allowing total fish concealment. Unlike corals with fixed skeletons, the tentacles of anemones are dynamic in morphology, in that previously digitiform tentacles become bulbous when adult fish are removed, and bulbous tentacles begin to lose their bulbs and elongate when colonized by fish (both within $1 \mathrm{~d}$ ), demonstrating that these anemones may rapidly alter tentacle morphology in response to fish presence. Dunn (1981) also concluded that contact with anemonefish can alter tentacle morphology in Entacmaea quadricolor, but that digitiform anemones lacking fish are common in the tropical Pacific, in contrast to our observations in the Red Sea. Factors affecting tentacle morphology in E. quadricolor may vary among coral reef regions, and could include irradiance levels (Delbeek 2002) and anemonefish presence, among others. Regardless, the association of many anemonefish species with this anemone (Fautin 1986, 1991, Fautin \& Allen 1997) is likely due in part to the ability of E. quadricolor to change tentacle morphology.

\section{Fish movement and host preference}

Most fish migrants in our field removal experiment were adults, including a pair that moved together, in contrast to previous conclusions that mainly juvenile anemonefish wander among anemones (Fautin 1991). Higher migration by adults than juvenile fish may occur due to 2 possible causes. (1) Distances between occupied and vacant anemones may be too large for most juvenile fish to safely traverse, in contrast to adult anemonefish that commonly move larger distances away from hosts when foraging (Allen 1972), as do damselfishes symbiotic with corals (Ben-Tzvi et al. 2009). Amphiprion clarkii are capable swimmers that may migrate up to $50 \mathrm{~m}$ among hosts (Hattori 1994) and may recruit from the plankton to small, less desirable hosts to avoid competition with heterospecific or larger conspecific anemonefish, then later migrate to large anemones to breed after achieving large body size (Hattori 2002). As members of the $A$. clarkii complex of anemonefishes (Allen 1972), A. 
bicinctus also may be highly mobile and thus able to migrate easily to Entacmaea quadricolor if space becomes available after growing large enough in Heteractis crispa. This habitat-switch strategy is used by coral gobies (Dirnwöber \& Herler 2007), but contrasts with that of less mobile anemonefishes such as A. percula (not in the A. clarkii complex; Elliott et al. 1999), in which conspecifics settle into adult habitats and form queues of juveniles leading to the inheritance of a breeding position (Buston 2004). (2) A second possible cause of lower mobility by juvenile than adult $A$. bicinctus may be aggression by adults, which oust smaller fish that attempt to migrate to an anemone, and prevent them from remaining in preferred anemones. We may not have detected migrations of juveniles if they were forced to return to their original anemones shortly after their arrival to preferred hosts. Unexpectedly, many fish that had migrated to $E$. quadricolor arrived from other nearby E. quadricolor, indicating low fidelity to individual anemones. Consistent with our observations on host species preference, there was a shorter time to colonization of empty E. quadricolor than of empty $H$. crispa, and overall recorded movement times $(<1$ up to $12 \mathrm{~d}$ ) were shorter than those documented for 2 other Amphiprion spp. in Papua New Guinea (8 to 38 $d_{i}$ Fautin 1992).

Complex movement patterns among anemones by Amphiprion bicinctus indicate that access to and competition for mates in part drive the observed patterns of host preference and migration. For example, when we removed an adult fish pair from an Entacmaea quadricolor, within $2 \mathrm{~d}$ the anemone was colonized by 3 new fish $(13,8.5$, and $6.5 \mathrm{~cm} \mathrm{TL})$, which left anemones with smaller fish. Though all 3 immigrant fish remained together at $12 \mathrm{~d}$ post-removal, the 2 smaller ones were aggressive toward one another, presumably fighting for permanent cohabitation with the larger adult. In another instance, we observed 9 movements among manipulated anemones by 4 fish over $11 \mathrm{~d}$, including the eviction of small fish — that had migrated to the anemones - by larger immigrant fish. Several dominant fish in our experiment migrated from hosts they cohabited with small subordinates into vacated hosts where they became the solitary fish, indicating that $A$. bicinctus may preferentially migrate to anemones in which they have the potential of securing a mate. This is similar to A. frenatus, which either maintain the same social rank or decrease in rank when migrating, and often gain a mate in the process (Hattori 2005), and is in contrast to juvenile A. clarkii, which often increase their social rank when migrating to new hosts (Hattori 1994, 2002).
Our laboratory experiments reveal that size-based aggressive behavior and competitive exclusion from preferred hosts appear to be major proximal mechanisms causing distributional patterns of Amphiprion bicinctus in the field. They confirm that solitary $A$. bicinctus prefer Entacmaea quadricolor to Heteractis crispa, but when interacting with a conspecific, the larger fish becomes dominant and prevents use of the preferred host by the smaller subordinate fish. Ecological impacts of this social hierarchy are well known for some anemonefishes: dominant adults relegate subordinates to less favorable positions or hosts, and monopolize space for both shelter and reproduction (Fautin 1986, Buston 2003a). In Japan, when interactions with subordinate $A$. perideraion become too energetically costly, competitively dominant $A$. clarkii emigrate to a new host rather than attempting to evict A. perideraion (Hattori 2002). This avoidance behavior and the resulting habitat segregation reduce competition and allow these 2 anemonefish species to coexist. Likewise, in Papua New Guinea, 9 anemonefish species coexist by either partitioning habitat among host species or among microhabitats that contain a single host species (Elliott \& Mariscal 2001). In the northern Red Sea, juvenile and adult $A$. bicinctus coexist through habitat segregation based on life stage. Because small $A$. bicinctus prefer $E$. quadricolor when alone under laboratory conditions, we conclude that in the field, juveniles would prefer to inhabit E. quadricolor, and thus do not reside in $H$. crispa based on an early lifestage preference for the latter species. Other species of Heteractis sea anemones in the Indo-Pacific region also appear to host only juvenile anemonefishes (Fautin 1991), but some may host all fish life stages (Fautin \& Allen 1997).

\section{CONCLUSIONS}

Chadwick \& Arvedlund (2005) proposed that Heteractis crispa may serve as nursery habitats for Amphiprion bicinctus because they host more juvenile fish than do Entacmaea quadricolor. To function as nursery habitats according to the nursery-role hypothesis (Beck et al. 2001), H. crispa must contribute more fish per unit area to the adult population than do E. quadricolor, requiring successful migration of fish between the hosts. At our site, H. crispa supported more juvenile fish per square meter of TCSA than E. quadricolor, and fish moved from $H$. crispa to nearby empty E. quadricolor; thus, $H$. crispa meet some criteria as nursery habitats for A. bicinc- 
tus. However, because habitats often serve as nurseries due to the developmental advantages they provide to juvenile fishes (Beck et al. 2001), our study indicates a potentially novel nursery situation: $H$. crispa may serve as nurseries because they are lesspreferred habitats. Even though E. quadricolor tend to be larger, more abundant, and preferred by $A$. bicinctus at all life stages, the area available for fish settlement is greater in $H$. crispa because they host few adult fish. Small $A$. bicinctus may settle into $H$. crispa and wait for vacancies to develop in E. quadricolor, but such vacancies likely are rare, as adult anemonefishes have potentially low mortality rates and long lifespans of up to 30 yr (Buston \& García 2007). If only a small percent of $A$. bicinctus make the transition from $H$. crispa to $E$. quadricolor, then H. crispa may be developmental dead-ends rather than nurseries.

We conclude that the sea anemone Heteractis crispa is a less-preferred host for anemonefish Amphiprion bicinctus than the anemone Entacmaea quadricolor, and that differences in body size, morphology, and behavior between these 2 host species appear to drive fish preference. We also conclude that competition for E. quadricolor structures populations of $A$. bicinctus in the northern Red Sea, with potential impacts on fish survival and growth due to variation in host traits. Patterns of microhabitat choice by cnidarian-associated fishes vary among geographic regions (Dirnwöber \& Herler 2007), so host use and preference by $A$. bicinctus may be more complex further south in the Red Sea, where a third host, H. magnifica, also occurs (Brolund et al. 2004). Our observations on morphology and behavior of E. quadricolor support the idea that this host is the most highly coevolved with fish associates, in addition to being inhabited by a higher diversity of anemonefishes than other anemones (Fautin 1991). Differences quantified here between the sea anemone hosts $E$. quadricolor and $H$. crispa, and between A. bicinctus and other anemonefishes which form queues (e.g. Buston 2004), highlight that there is no single model for anemonefish symbioses (Fautin 1991) and that much remains unknown about these complex mutualisms on coral reefs. Further investigation on the dynamics of anemonefish symbioses will likely yield important insights into the ecology and social dynamics of fishes, as well as the mechanisms controlling the evolution of symbioses.

Acknowledgements. We thank the staff at the Marine Science Station at Aqaba, Jordan, for their hospitality and use of facilities. J. Szczebak, M. Schneider, and other partici- pants of the NSF International Research Experiences for Students (IRES) program in Jordan contributed valuable field assistance. Members of the Chadwick laboratory at Auburn University assisted with aquarium animal care. We thank 3 anonymous referees for helpful commentary on this manuscript. This research was funded by NSF-OISE Grant \#0733604 to N.E.C., and an Undergraduate Research Fellowship and a Department of Biological Sciences Undergraduate Research Fund for Excellence grant from Auburn University to B.D. This is Contribution \#89 of the Auburn University Marine Biology Program.

\section{LITERATURE CITED}

Allen GR (1972) The anemonefishes: their classification and biology, 2nd edn. T.F.H. Publications, Neptune City, NJ Arvedlund M, Nielsen LE (1996) Do the anemonefish Amphiprion ocellaris (Pisces: Pomacentridae) imprint themselves to their host sea anemone Heteractis magnifica (Anthozoa: Actinidae)? Ethology 102:197-211

> Arvedlund M, McCormick MI, Fautin DG, Bildsøe M (1999) Host recognition and possible imprinting in the anemonefish Amphiprion melanopus (Pisces: Pomacentridae). Mar Ecol Prog Ser 188:207-218

Bay LK, Jones GP, McCormick MI (2001) Habitat selection and aggression as determinants of spatial segregation among damselfish on a coral reef. Coral Reefs 20: 289-298

> Beck MW, Heck KL Jr, Able KW, Childers DL and others (2001) The identification, conservation, and management of estuarine and marine nurseries for fish and invertebrates. Bioscience 51:633-641

Ben-Tzvi O, Kiflawi M, Polak O, Abelson A (2009) The effect of adult aggression on habitat selection by settlers of two coral-dwelling damselfishes. PLoS ONE 4:e5511

Bollinger EK, Switzer PV, Pfammatter J, Allen J (2008) Group formation and anemone use in captively reared anemonefish (Amphiprion frenatus). Ichthyol Res 55: 394-398

Bonin MC, Srinivasan M, Almany GR, Jones GP (2009) Interactive effects of interspecific competition and microhabitat on early post-settlement survival in a coral reef fish. Coral Reefs 28:265-274

Brolund TM, Tychsen A, Nielsen LE, Arvedlund M (2004) An assemblage of the host anemone Heteractis magnifica in the northern Red Sea, and distribution of the resident anemonefish. J Mar Biol Assoc UK 84:671-674

Buston P (2003a) Forcible eviction and prevention of recruitment in the clown anemonefish. Behav Ecol 14:576-582

Buston P (2003b) Size and growth modification in clownfish. Nature 424:145-146

> Buston PM (2004) Territory inheritance in clownfish. Proc R Soc Lond B 271:S252-S254

> Buston PM, García MB (2007) An extraordinary life span estimate for the clown anemonefish Amphiprion percula. J Fish Biol 70:1710-1719

> Chadwick NE, Arvedlund M (2005) Abundance of giant sea anemones and patterns of association with anemonefish in the northern Red Sea. J Mar Biol Assoc UK 85: 1287-1292

- Cleveland A, Verde EA, Lee RW (2011) Nutritional exchange in a tropical tripartite symbiosis: direct evidence for the transfer of nutrients from anemonefish to host anemone and zooxanthellae. Mar Biol 158:589-602 
Delbeek JC (2002) The effects of lighting on bulb-tip development in the bulb tentacle anemone, Entacmaea quadricolor (Rüppell and Leukart, 1828), with additional observations on sexual reproduction in E. quadricolor and Stichodactyla gigantea (Forsskål, 1775). Adv Aquarist 1:Nov 2002. Available at: www.advancedaquarist.com/ issues/nov2002/feature.htm (accessed February 2012)

Dirnwöber M, Herler J (2007) Microhabitat specialisation and ecological consequences for coral gobies of the genus Gobiodon in the Gulf of Aqaba, northern Red Sea. Mar Ecol Prog Ser 342:265-275

> Dunn DF (1981) The clownfish sea anemones: Stichodactylidae (Coelenterata: Actinaria) and other sea anemones symbiotic with pomacentrid fishes. Trans Am Philos Soc 71:3-115

Elliott JK, Mariscal RN (2001) Coexistence of nine anemonefish species: differential host and habitat utilization, size and recruitment. Mar Biol 138:23-36

Elliott JK, Mariscal RN, Roux KH (1994) Do anemonefishes use molecular mimicry to avoid being stung by host anemones? J Exp Mar Biol Ecol 179:99-113

Elliott JK, Lougheed SC, Bateman B, McPhee LK, Boag PT (1999) Molecular phylogenetic evidence for the evolution of specialization in anemonefishes. Proc R Soc Lond B 266:677-685

Fautin DG (1986) Why do anemonefishes inhabit only some host actinians? Environ Biol Fishes 15:171-180

Fautin DG (1991) The anemonefish symbiosis: What is known and what is not. Symbiosis 10:23-46

Fautin DG (1992) Anemonefish recruitment: the roles of order and chance. Symbiosis 14:143-160

Fautin DG, Allen GR (1997) Anemonefishes and their host sea anemones, 2nd edn. Western Australian Museum, Perth

Fishelson L (1970) Littoral fauna of the Red Sea: the population of non-scleractinian anthozoans of shallow waters of the Red Sea (Eilat). Mar Biol 6:106-116

Forrester GE, Evans B, Steele MA, Vance RR (2006) Assessing the magnitude of intra- and interspecific competition in two coral reef fishes. Oecologia 148:632-640

Fricke HW (1983) Social control of sex: field experiments with the anemonefish Amphiprion bicinctus. Z Tierpsychol 61:71-77

Fukui Y (1973) Some experiments on the symbiotic association between sea anemone and Amphiprion. Publ Seto Mar Biol Lab 20:419-430

Hattori A (1994) Inter-group movement and mate acquisition tactics of the protandrous anemonefish, Amphiprion clarkii, on a coral reef, Okinawa. Jpn J Ichthyol 41: 159-165

Editorial responsibility: Charles Birkeland, Honolulu, Hawaii, USA
Hattori A (2002) Small and large anemonefishes can coexist using the same patchy resources on a coral reef, before habitat destruction. J Anim Ecol 71:824-831

Hattori A (2005) High mobility of the protandrous anemonefish Amphiprion frenatus: nonrandom pair formation in limited shelter space. Ichthyol Res 52:57-63

> Holbrook SJ, Schmitt RJ (2002) Competition for shelter space causes density-dependent predation mortality in damselfishes. Ecology 83:2855-2868

> Holbrook SJ, Schmitt RJ (2005) Growth, reproduction and survival of a tropical sea anemone (Actiniaria): benefits of hosting anemonefish. Coral Reefs 24:67-73

Holbrook SJ, Forrester GE, Schmitt RJ (2000) Spatial patterns in abundance of a damselfish reflect availability of suitable habitat. Oecologia 122:109-120

Khalaf MA, Al-Horani FA, Al-Rousan SA, Manasrah RS (2006) Community structure of the family Pomacentridae along the Jordanian coast, Gulf of Aqaba, Red Sea. Zool Middle East 37:47-62

> Mergner H, Schuhmacher H (1974) Morphologie, Ökologie und Zonierung von Korallenriffen bei Aqaba (Golf von Aqaba, Rotes Meer). Helgol Wiss Meeresunters 26: 238-358

> Porat D, Chadwick-Furman NE (2004) Effects of anemonefish on giant sea anemones: expansion behavior, growth, and survival. Hydrobiologia 530/531:513-520

Porat D, Chadwick-Furman NE (2005) Effects of anemonefish on giant sea anemones: ammonium uptake, zooxanthella content and tissue regeneration. Mar Freshwat Behav Physiol 38:43-51

Robertson DR (1996) Interspecific competition controls abundance and habitat use of territorial Caribbean damselfishes. Ecology 77:885-899

Roopin M, Chadwick NE (2009) Benefits to host sea anemones from ammonia contributions of resident anemonefish. J Exp Mar Biol Ecol 370:27-34

Schiemer L, Niedermüller S, Herler J (2009) The influence of colony size and coral health on the occupation of coralassociated gobies (Pisces: Gobiidae). Coral Reefs 28: 137-142

Srinivasan M, Jones GP, Caley MJ (1999) Experimental evaluation of the roles of habitat selection and interspecific competition in determining patterns of host use by two anemonefishes. Mar Ecol Prog Ser 186: 283-292

Szczebak JT (2011) Nocturnal ecophysiology of the anemonefish-sea anemone mutualism: patterns of dark oxygen consumption and symbiont behavior at night. MS thesis, Auburn University, Auburn, AL

Submitted: March 29, 2012; Accepted: July 29, 2012

Proofs received from author(s): September 10, 2012 